\title{
Characterisation of residual stress state and distortion in welded plates stress engineered by local mechanical tensioning
}

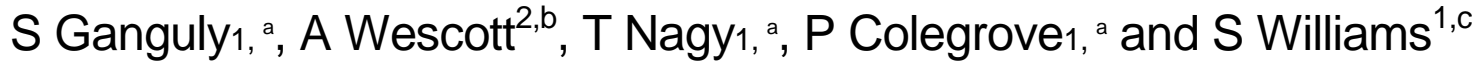 \\ Welding Engineering and Laser Processing Centre, Cranfield University, Cranfield, Bedford, \\ 'UK Advanced Technology Centre, BAE Systems, Filton, Bristol, UK

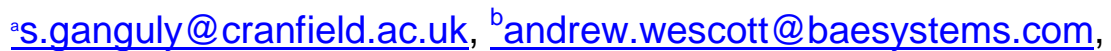 \\ ct.nagy@cranfield.ac.uk, ${ }^{\mathrm{d}}$.a.colegrove@cranfield.ac.uk, ${ }^{\mathrm{e}}$ S.williams@cranfield.ac.uk
}

Keywords: Residual stress, local mechanical tension, distortion, neutron diffraction.

\begin{abstract}
Local mechanical tensioning is one of the most efficient and industrially relevant stress engineering techniques to modify weld residual stress field and subsequently reduce buckling distortion. However, application of rolling load and its magnitude need to be optimised for an energy efficient rolling process. In the present study gas metal arc butt welded plates of low carbon mild steel were rolled by a dual roller in different rolling configuration (top and reverse side rolling) and with different magnitude of rolling load. All the plates were rolled post welding. Residual strain profiles of the post weld rolled plates were measured, using the SALSA strain scanner, and the inplane stress were characterized. Average distortion of the rolled plates was correlated with the residual stress state. Reverse rolling was found to be more effective in removing distortion while the stress profile did not show any significant reduction of the peak stress.
\end{abstract}

\section{Introduction}

Welding of any metallic components results into formation of a variable distribution of residual stress field across the weld and the heat affected zone. Residual stresses are self balancing and typically show a tensile type distribution in and around the weld which is balanced by formation of a large compressive stress field further out in the parent material [1]. The balancing compressive stress field generated when exceeds the critical buckling load results into severe buckling distortion of the fabricated component and often needs further working to remove the distortion. With advancement in design efficient structural materials the problem of weld distortion is becoming more severe as thinner material is used for structural applications. Therefore, it is vitally important to device measures to mitigate the residual stress in order to prevent excessive distortion after welding and subsequently to prevent expensive reworking or rejection of welded components. There are several stress engineering mechanisms by which the balancing compressive stress field could be removed or reduced to prevent distortion [1]. However, for industrial suitability the method has to be robust, efficient and cost effective. Local mechanical tensioning (LMT) is one of the several techniques that are being widely researched because of its industrial suitability [2;3]. In local mechanical tensioning, as the name suggests, a longitudinal stretch is applied locally on the weld zone by means of rolling. The longitudinal stretch, depending on the magnitude and time of application i.e. pre/post/in-situ rolling, interacts with the existing (or to be generated) thermal stress field to reduce/eliminate or even reverse the sign of the stress i.e. changing from a tensile stress field to a compressive stress field. In the present experiment local mechanical tensioning in the form of dual roller rolling process was applied to gas metal arc butt welded (GMAW) plates of low carbon structural steel. Rolling on the plates was carried out after welding. Principal residual strains, in all the three directions, of the rolled butt welded plates were measured and then in-plane stresses were analysed assuming plane stress condition. The measured stress was compared with an aswelded sample to understand the modification of stress profile. The average distortion of the different GMAW plates were then compared and correlated with the obtained stress profiles. The suitability of the different roller configuration and rolling load was then compared based on the measured stress and average distortion. 


\section{Specimen Geometry and Preparation: Welded Specimens:}

Low carbon steel plates butt welded by GMAW process were manufactured at the Welding Engineering and Laser Processing Centre, Cranfield University. The average dimension of the welded plates were 1000 (Long) $\times 500$ (Wide) $\times 4$ (Thick) $\mathrm{mm}$. A Lincoln power wave digital control GMAW machine was used for precise control of heat input for the different welds produced. The welds were produced with a nominal heat input of $0.84 \mathrm{KJ} / \mathrm{mm}$.

\section{Local Mechanical Tensioning}

Local mechanical tensioning was induced by rolling processes as shown in fig. 1. The dual roller the force was applied symmetrically on both sides of the weld line. In the presented work the GMAW butt welded plates were reported where the dual flat rollers were used to apply the local mechanical tensioning. In post weld condition rolling was done either on the top surface or on the reverse side i.e. the weld root side. Table 1 shows the different process parameters (roller configuration and rolling process) followed for the different plates.

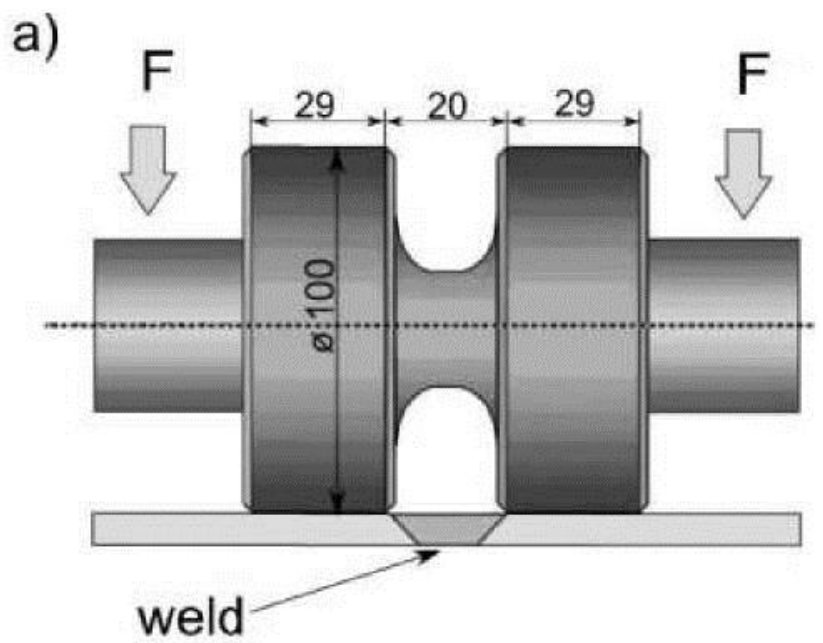

Fig. 1 - Configuration of the dual roller applied for local mechanical tensioning (Note rolling was carried out both from the top and also from the reverse side)

\section{Strain Measurement:}

Neutron diffraction was performed to analyse the residual stress state across the welds along the mid-plane and close to the surface (see table 1). An incoming beam of $2 \times 2 \mathrm{~mm}^{2}$ was used and a 2 $\mathrm{mm}$ slit in front of the detector maintained the spatial resolution in the through thickness direction. A monochromatic incoming beam of $1.74 \AA$ was used during the experiment. The $\{211\}$ family of crystallographic plane was measured for the low carbon steel specimens. The choice of the crystallographic plane is based on their characteristics of following the macroscopic strain variation

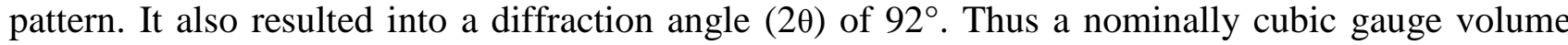
was obtained which gave an excellent spatial resolution in all the three measured directions. Stress was analysed with the reasonable assumption that plane stress condition exists with the out-of-plane direction unable to hold any stress due to insufficient dimension $(\sigma \mathrm{N}=0)$. The stress free lattice parameter $(\mathrm{a} 0)$ and the in-plane stresses were determined using the following equations;

$$
\begin{aligned}
& a_{0}=\frac{1-v}{1+v} a_{N}+\frac{v}{1+v}\left(a_{L}+a_{T}\right) \\
& \sigma_{L}=\frac{E}{\left(1-v^{2}\right)}\left(\varepsilon_{L}+v \varepsilon_{T}\right)
\end{aligned}
$$

where aL, $\mathrm{aT}$, and $\mathrm{aN}$ are the measured lattice parameter and $\sigma \mathrm{L}$ is the longitudinal stress and $\mathrm{EL}$ and ET are the strain measured in longitudinal and transverse directions respectively. 
Table1: Different processing parameters and measurement details

\begin{tabular}{|c|c|c|c|c|c|c|}
\hline $\begin{array}{c}\text { Sample } \\
\text { No. }\end{array}$ & $\begin{array}{c}\text { Weld } \\
\text { process }\end{array}$ & $\begin{array}{c}\text { Roller } \\
\text { type }\end{array}$ & $\begin{array}{c}\text { Rolling } \\
\text { Configuration }\end{array}$ & $\begin{array}{c}\text { Rolling } \\
\text { load/ } \\
(\mathrm{KN})\end{array}$ & $\begin{array}{c}\text { Rolling } \\
\text { process }\end{array}$ & $\begin{array}{c}\text { Measurement } \\
\text { position }\end{array}$ \\
\hline 1 & GMAW & Dual & Reverse & 50 & $\begin{array}{c}\text { Post } \\
\text { weld }\end{array}$ & $\begin{array}{c}\text { Mid-plane and } \\
\text { near surface }\end{array}$ \\
\hline 2 & GMAW & Dual & Top & 50 & $\begin{array}{c}\text { Post } \\
\text { weld }\end{array}$ & $\begin{array}{c}\text { Mid-plane and } \\
\text { near surface }\end{array}$ \\
\hline 3 & GMAW & Dual & Reverse & 70 & $\begin{array}{c}\text { Post- } \\
\text { weld }\end{array}$ & $\begin{array}{c}\text { Mid-plane and } \\
\text { near surface }\end{array}$ \\
\hline
\end{tabular}

\section{Distortion Measurement:}

Distortion measurement was carried using a height gauge at eight positions around the welded plate, in each corner, midway along the plate length and at either end of the weld centreline as shown in fig. 2. The out-of-plane distortion (distance from the dotted line in fig. 2) for each of these points was measured by the gauge and then averaged to determine the distortion index of the plate.

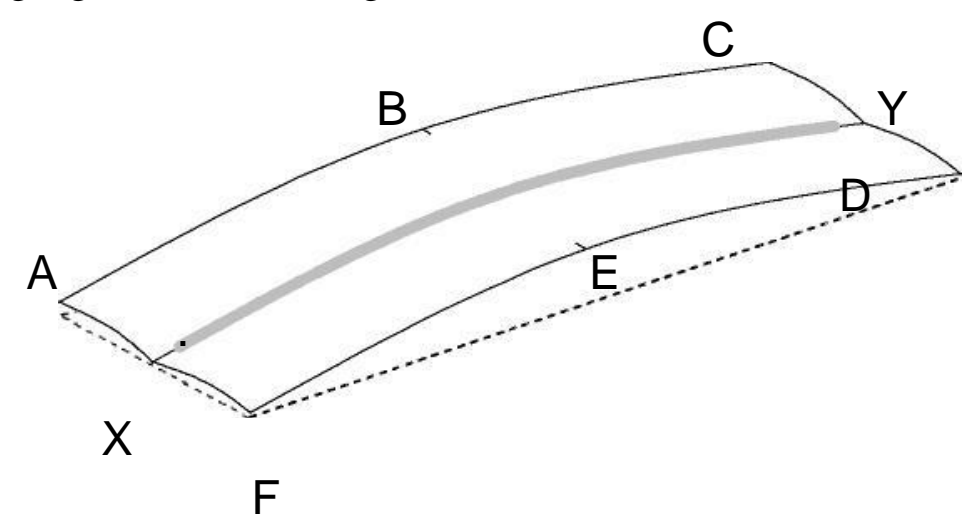

Fig. 2 - Schematic represenation of distortion index measurement positions

\section{Results and Discussion:}

The residual stress profile and magnitude in the as welded GMAW plate is shown in fig. 3. The roller locations were superimposed on top of the stress profile to indicate the load application position by the dual rollers.

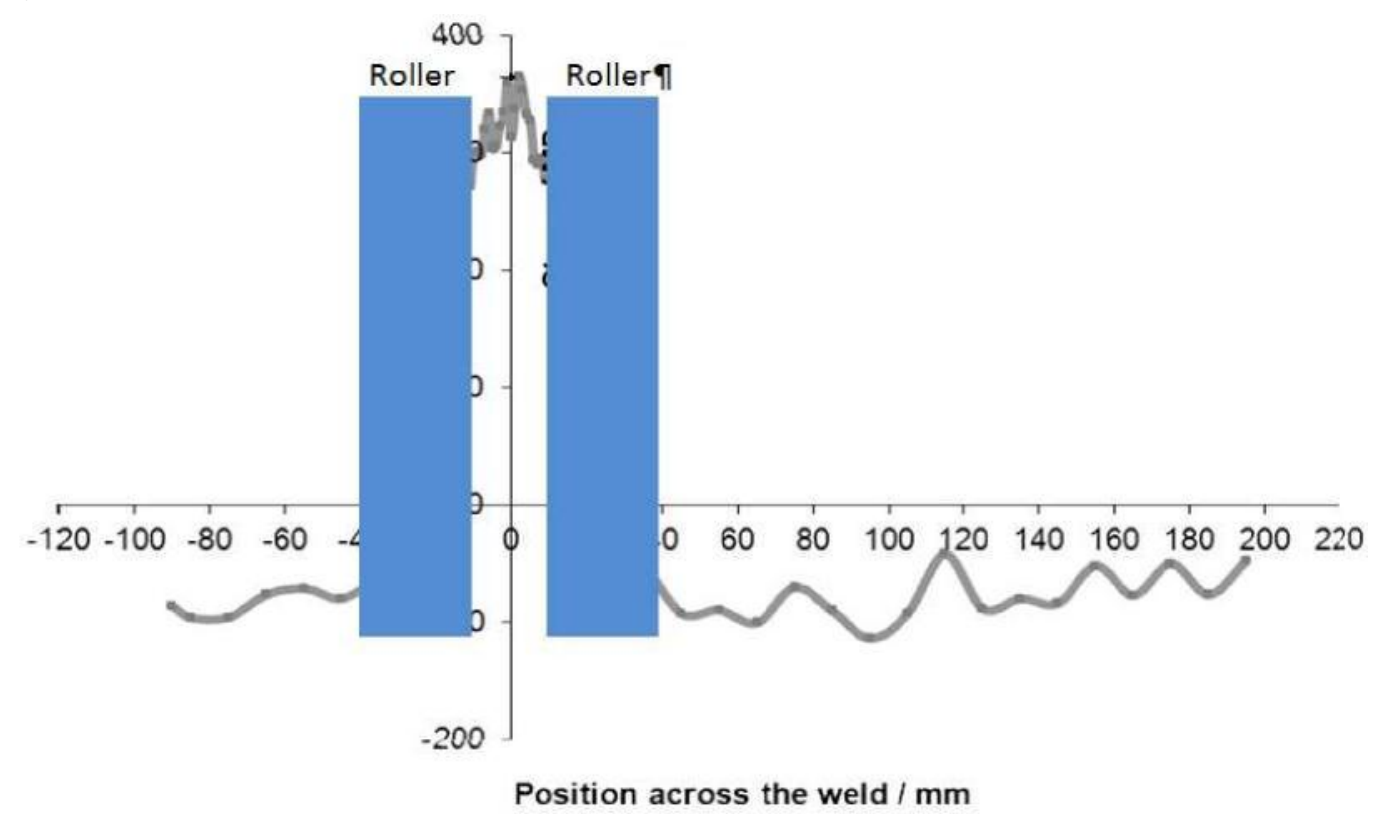

Fig. 3 - Residual stress distribution in the mid-plane of the as-welded specimen and approximate position of tension load application by the dual roller 
The resulting residual stress profiles for the post weld rolled specimens is shown in fig. 4.

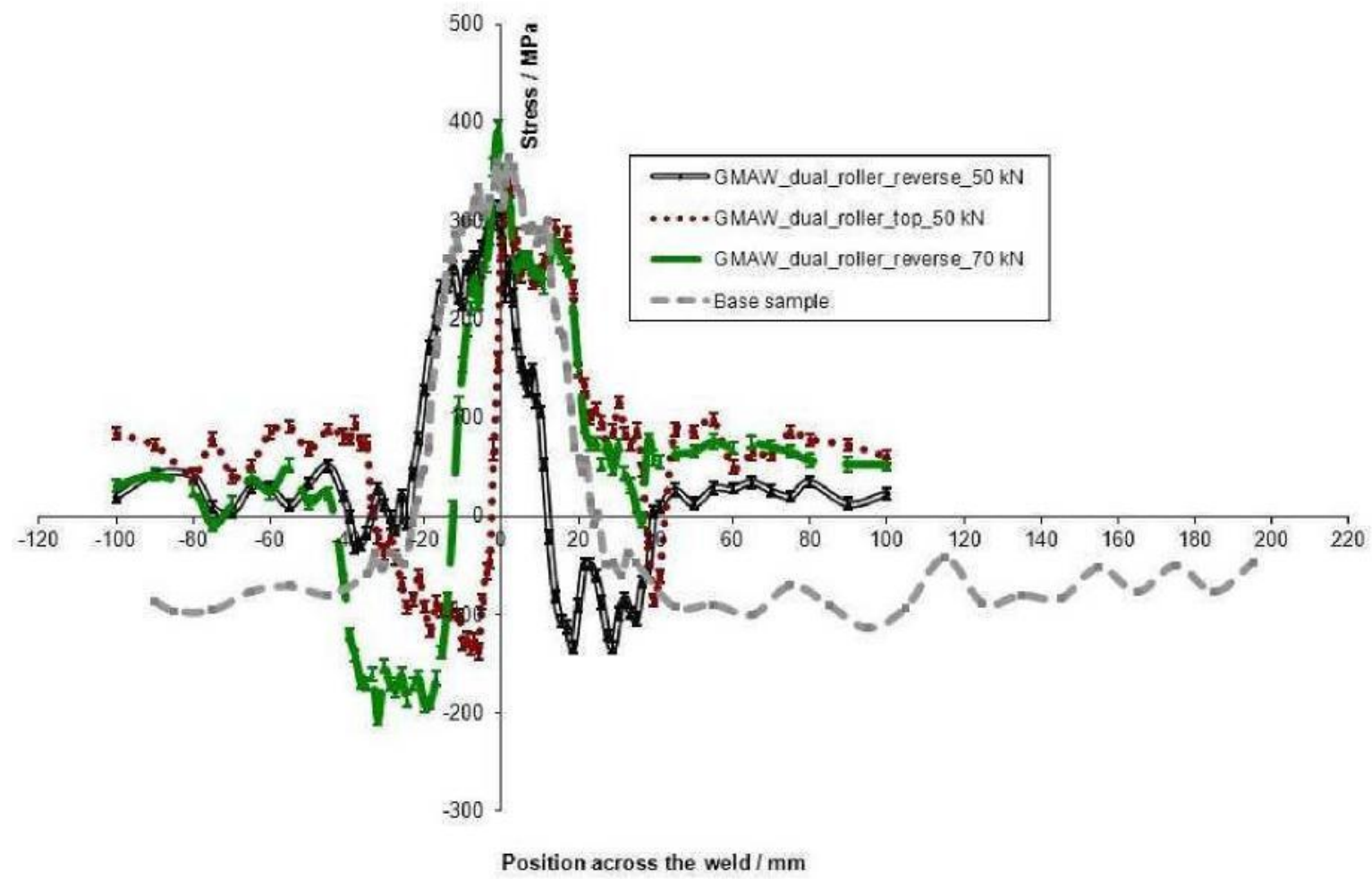

Fig. 4 - Modified stress distribution pattern in the mid-plane of the post weld rolled specimens.

It can be seen that dual roller configuration essentially modified the stress distribution profile, across the weld, while the peak stress magnitude did not reduce significantly. The symmetric stress profile across the weld was changed and the stress distribution after rolling has changed into skewed distribution across the weld after the rolling operation. This could be due to fact that the area of contact of one roller on one side of the specimen is more as compared to the other side. This will lead to an asymmetry in the applied load and, therefore, while one side of the weld is showing a compressive stress due to plastic deformation the other side is showing a relatively higher stress magnitude. Fig. 5 shows the change in distortion index for the various specimens. The improvement in distortion was calculated based on the distortion index of the as-welded specimen.

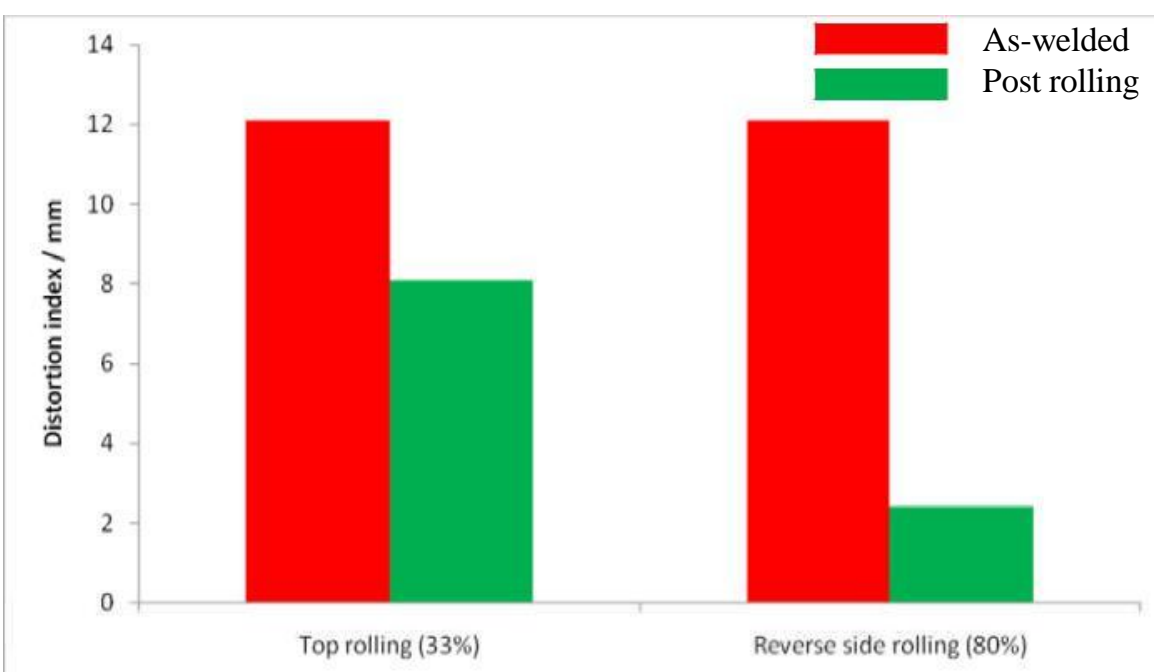

Fig. 5- Reduction in distortion for top and reverse rolling (Top rolling resulted in reduction of the distortion index by $33 \%$ while in case of reverse side rolling distortion index was reduced by $80 \%$ ) 
The reverse rolled plates showed a significant improvement in the reduction of distortion of about $80 \%$ as compared to top rolled plate which only reduced distortion by $33 \%$. This could be due to better contact between roller and plates in reverse rolling as in fig. 4 it can be seen that the compressive stress region is to some extent lower in the case of reverse rolled specimen as compared to top rolling.

\section{Conclusion:}

- The study showed post weld dual roller tensioning can be effective in reducing distortion.

- The stress profile showed an asymmetric distribution after rolling probably due to imbalanced transfer of load in the two rollers.

- Reverse rolling has shown significant better performance in reducing distortion as compared to top rolling. This could be due to greater contact area between the roller and the plates in reverse rolling configuration because of angular distortion of the plate.

- Single roller load application would be studied in future. This is necessary for GMAW welds due to the protruded bead geometry.

\section{References}

[1] Williams, S. W. and Steuwer, A. (2010), "Residual stresses in friction stir welding", Woodhead publishing limited, Cambridge, UK, pp. 215.

[2] Altenkirch, J., Steuwer, A., Withers, P. J., Williams, S. W., Poad, M. and Wen, S. W. (2009), "Residual stress engineering in friction stir welds by roller tensioning", Science and Technology of Welding and Joining, vol. 14, no. 2, pp. 185-192.

[3] Wen, S. W., Colegrove, P. A., Williams, S. W., Morgan, S. A., Wescott, A. and Poad, M. (2010), "Rolling to control residual stress and distortion in friction stir welds", Science and Technology of Welding and Joining, vol. 15, no. 6, pp. 440-447. 